\title{
ИТАЛИЯ ВО ГЛАВЕ ЕВРОКРИТИКОВ ${ }^{1}$
}

\begin{abstract}
Аннотация. Италия - единственная крупная страна EC, где у власти находится еврокритическое коалиционное правительство, бросающее открытый вызов экономической политике Евросоюза. Оба его лидера, соперничающие между собой, развивают идеи «обновления Европь»» и стремятся создать собственные группь в составе будущего Европейского парламента. Итальянские «европеисты» не смогут быть противовесом еврокритикам на этих выборах. Деловой мир Италии озабочен упрощённым подходом политического руководства к проблемам страны в ухудшающейся экономической ситуащии. Ближайшее будущее продемонстрирует реальную значимость альтернативы, предлагаемой итальянским правительством.
\end{abstract}

Ключевые слова: Италия, еврокритики, Европейский парламент, выборы, Сальвини, Ди Майо.

Италия - единственная крупная страна ЕС, где в результате парламентских выборов (4 марта 2018 г.) к власти пришла коалиция еврокритиков, объединившая «суверенистскую» Лигу и считавшее себя антисистемным «Движение 5 Звёзд» (ДПЗ). По данным Евробарометра, население этой страны скептически оценивает своё членство в Евросоюзе: 45\% - «плохо», $43 \%$ - «хорошо», против средней по ЕС положительной оценки $62 \%^{2}$. Доверие к ЕС, в марте 2010 г. достигавшее $73 \%$, упало в феврале 2019 г. до $37 \%{ }^{3}$.

Разработанный новым итальянским «правительством перемен» бюджет на 2019 г. стал открытым вызовом бюджетным правилам ЕС. В нём были заложены масштабное расширение расходов на социальные цели («доход от гражданства», более льготный пенсионный режим), сокращение налогового бремени (введение плоской шкалы) и увеличение государственных капиталовложений в инфраструктуру. Еврокомиссия отвергла этот вариант; после длительных трудных переговоров был достигнут хрупкий компромисс, не устраняющий возможности штрафных санкций. Итальянское правительство отстояло, таким образом, свою роль «оппозиционера», борющегося за утверждение в ЕС альтернативы нынешнему, неолиберальному экономическому курсу.

Эта позиция взята за основу и в ходе кампании по выборам в Европарламент. «Мы разбудили Европу», - заявляет М. Сальвини, уверенный, что нынешний политический поворот

(C) Авилова Агнесса Викторовна - кандидат экономических наук, ведущий научный сотрудник Научно исследовательского Института мировой экономики и международных отношений им. Е.М. Примакова РАН. Aдрес: 117997, Россия, Москва, ул. Профсоюзная, д. 23. E-mail: avi@imemo.ru.

DOI: http://dx.doi.org/10.15211/vestnikieran220193843

1 Этот термин объединяет несколько синонимичных понятий, различающихся оттенками негативного отношения к сегодняшнему ЕС: евроскептики (см. Грибовский В.С. «Евроскептицизм как политическая тенденция начала XXI века», где используются оба термина - еврокритики и евроскептики. URL: https://riss.ru/analytics/25709), суверенисты (см. Зафесова А., Минаков М. «Чем Италия угрожает объединённой Европе». URL: https://carne gie.ru/commentary/76634), антисистемное движение (см. «СМИ: «Движение 5 звёзд» уступает на выборах в Италии коалиции правоцентристов». URL: https://tass.ru/mezhdunarodnaya-panorama/5007199).

${ }^{2}$ Elezioni europee 2019. Servizio stampa, Direzione generale della Comunicazione. URL: www.europarl.europa.eu/ pdfs/news/expert/2018/8/service/20180820SRV10205/elections-press-kit-it.pdf.

${ }_{3}^{3}$ Fabbrini S. Riforme in Europa, non soltanto in Italia. Il Sole 24 Ore, 31.03.2019. 
Италии знаменует собой начало новой эпохи, определяя ход общественного развития континента на 50 лет вперёд. «За Европу здравого смысла» - таков был лозунг конференции, проведённой им 8 апреля с участием единомышленников из ФРГ, Дании и Финляндии. Предстоящие выборы, сказал Сальвини, станут референдумом об отношении народа к элитам. Цель итальянского проекта - спасение Европы для будущих поколений: защита семьи, труда, евро-пейской идентичности, национальных суверенитетов. Необходимо прекратить массовую иммиграцию и позаботиться в первую очередь о собственных безработных, о молодёжи. Ныне-шнее руководство ЕС предало идеи, заложенные в Маастрихтском договоре. Итальянское правительство хочет народовластия, вместо власти банкиров. Для реализации этих задач не-обходимо создать в Европарламенте ведущую группу, объединившись невзирая на частичные разногласия. В поддержку этого проекта 18 мая, за неделю до выборов, в Милане будет проведена общеевропейская манифестация «суверенистов».

Характерно, что Лига и ДПЗ идут на эти выборы порознь, и не только из-за различия акцентов в их партийных программах, в равной мере популистских. Причина заключается в их соперничестве почти по всем вопросам практического руководства страной (что сильно тормозит проведение обещанных ими преобразований). Европейские выборы должны стать для обоих испытанием, результаты которого во многом определят соотношение сил внутри коалиции.

Оба лидера ищут в странах ЕС союзников, рассчитывая занять более выгодное положение в наднациональном раскладе политических сил. Если для Сальвини общим знаменателем для объединения сторонников становится иммиграционная политика, поскольку в экономических вопросах «суверенисты» северных стран не сочувствуют своим собратьям с Юга, то ДПЗ выстраивает свой фронт на идеях прямой демократии, защиты «made in» (национального малого бизнеса), европейского минимума заработной платы и «зелёной экономики».

В настоящее время опросы показывают устойчивое доминирование Лиги и ДПЗ во вкусах итальянских избирателей (\% к числу полученных голосов) $)^{1}$ :

\begin{tabular}{|l|c|}
\hline Лига & 32,1 \\
\hline ДПЗ & 22,7 \\
\hline Демократическая партия & 20,5 \\
\hline Вперёд, Италия & 10,0 \\
\hline Братья Италии & 5,3 \\
\hline + Европа & 2,7 \\
\hline Итальянская левая & 2,7 \\
\hline Прочие & 4,0 \\
\hline
\end{tabular}

Соотношение сил между Лигой и ДПЗ внутри страны радикально изменилось после мартовских выборов 2018 г., принёсших крупную победу ДПЗ (31\% против 17\% у Лиги). Перевес Лиги обозначился в ходе четырёх подряд побед на региональных выборах в областях Юга, где прежде абсолютно доминировало ДПЗ. В Италии муссируются слухи, что в случае успеха на европейском уровне Лига может инициировать досрочные парламентские выборы и вместе с партнёрами по правоцентристской коалиции - партиями «Вперёд, Италия» и Братья Италии - добьется дальнейшего сдвига страны вправо, создав правительство большинства.

Как ДПЗ, так и особенно Лига в силу их нынешнего политического веса в Италии могут рассчитывать на приращение числа евромандатов и большее представительство в европейских структурах. Согласно прогнозам, Лига может почти пятикратно увеличить свое присутствие, получив 29 мандатов и образовав крупнейшее, после немецкой ХДП, национальное

\footnotetext{
${ }^{1}$ Elezioni europee 2019, I sondaggi di Sky TG 24: Lega al 32,1, Pd vicino al M5s. URL: https://tg24.sky.it/politica/ photogallery/2019/04/01/sondaggi-elezioni-europee-2019.html\#0.
} 
партийное представительство в Европарламенте; ожидается и продвижение ДПЗ - до 26 мандатов ${ }^{1}$.

Основное препятствие для планов Сальвини заключается в том, что его потенциальные союзники - «суверенисты» (французское Национальное объединение, Альтернатива для Германии, польское Право и справедливость, Шведские демократы, австрийская Народная партия и др.), входящие в разные еврогруппы, идейно расходятся по важным для них вопросам. Так, французских и польских «суверенистов» разделяет отношение к России, а венгерский лидер, хотя и восхищается антииммигрантской политикой Сальвини, пока не хочет терять свою принадлежность к Европейской народной партии. Тем не менее, перспектива создания самостоятельной еврогруппы под руководством Сальвини считается реальной. ДПЗ же, стремящееся сформировать свою еврогруппу («ни правых, ни левых», по определению Ди Майо), пока может твёрдо рассчитывать только на трёх участников, способных преодолеть избирательный барьер: хорватскую Zivi Zid, польскую Kukiz'15 и греческую AKKEL (вместо семи, требуемых правилами Европарламента), так как электоральная поддержка остальных возможных союзников не слишком велика. Но Ди Майо не исключает и варианта присоединения к центристской части будущей парламентской партийной структуры, с тем чтобы играть в ней роль «балансирующего компонента». Он надеется после выборов получить поддержку тех депутатов-либералов, которые не захотят быть союзниками партии Э. Макрона.

С проевропейских позиций на эти выборы идут Демократическая партия и несколько небольших левых группировок. ДП ввела в свой партийный символ слова «Мы европейцы»заголовок манифеста, с которым выступило её руководство. В предвыборной программе ДП выдвигается идея чрезвычайного плана капиталовложений в человеческий капитал, НИОКР, инфраструктуру, возобновляемые источники электроэнергии, социальную сферу, а также близкий итальянскому предпринимательству лозунг борьбы с налоговым демпингом (налогообложения прибыли крупных ТНК по месту её получения, а не в льготных гаванях $)^{2}$. После смены лидера, которым стал Н. Дзингаретти, поддержка ДП выросла, однако часть её электората считает необходимой более резкую критику нынешнего ЕС, а часть, вероятно, не придёт голосовать, считая себя покинутой как своими, так и тем более европейскими политиками. Левые силы Италии идут на выборы порознь, и реальным противовесом евроскептикам они стать не могут: Демократической партии эксперты обещают сокращение евромандатов до 16 , то есть вдвое ${ }^{3}$, а таким группировкам, как +Европа и Итальянская левая, вряд ли удастся преодолеть избирательный барьер.

Стоит отметить, как важное событие во «втором эшелоне» правых сил, новый выход на политическую сцену С. Берлускони. Он досрочно освободился от судебного запрета избираться на общественные должности, введённого в 2013 г., и заявляет о своей готовности работать в европейских структурах. От партии Братья Италии в Европарламент баллотируется Кайо Муссолини, правнук бывшего вождя нации. Заметно присутствие профашистской Каза Паунд, заявляющей, что ЕС - «тюрьма, из которой необходимо выйти».

К выдвижению кандидатов Лига и ДПЗ подошли по-разному. Списки Лиги по всем территориальным избирательным округа́м ${ }^{4}$ возглавит М. Сальвини. ДПЗ, верная своему принци-

\footnotetext{
1 Comprendre l'Europe. URL: https://www.touteleurope.eu/actualite/a-quoi-ressemblera-lefutur-parlement-europeen. html; http://www.today.it/politica/candidati-elezioni-europee-2019.html. На выборах 2014 г. Лига получила 5 мандатов против 17 у ДПЗ, которое уступало тогда только Демократической партии (31) и опережало правоцентристскую «Вперёд, Италия» (11).

${ }_{3}^{2}$ Patta E. Pd: rischio Italexit, giu' il cuneo sul lavoro. Il Sole 24 Ore, 10.04.2019.

3 Comprendre 1'Europe. URL: https://www.touteleurope.eu/actualite/a-quoi-ressemblera-le futur-parlement-europeen. html.

${ }^{4}$ Италия разделена на пять территориальных избирательных округов: Северо-Запад (20 мандатов), Северо-ВосНаучно-аналитический вестник ИЕ РАН, 2019, №2
} 
пу работы с электоратом через интернет, провела отбор в два тура, после чего Ди Майо объявит списки номинантов. По его словам, они «удивят» общественность, причём все списки возглавят женщины. «Вперёд, Италия» в четырёх округах выдвинет первым номером С. Берлускони (что фактически гарантирует ему получение евромандата), пятый отдан его другу А. Тайани, экс-главе Европарламента.

Свой совместный документ, с призывом к населению участвовать в предстоящих выбоpax, опубликовали Конфедерация итальянских промышленников (Конфиндустрия) и три ведущих профсоюза. В нём выражены следующие приоритеты: продолжение процесса европейской интеграции, с тем чтобы завершить создание единого рынка и экономического союза, отвечающих условиям конкуренции в новом глобальном контексте; защита европейских ценностей и укрепление институтов, включая первостепенную роль Европарламента, в целях более эффективного управления; упрочение европейской солидарности в вопросах поддержания доходов и занятости, общей иммиграционной политики, гармонизации и конвергенции налоговых режимов; укрепление демократии, развитие социального диалога и защита социальной справедливости. Не отдавая явного предпочтения каким-либо политическим силам, авторы соглашения высказываются за реформы, финансируемые с участием ЕС путём выпуска еврооблигаций, и за отказ от жёсткого ограничения бюджетного дефицита «потолком» в $3 \% \mathrm{BB}^{1}$.

В этом документе нашла отражение озабоченность предпринимателей и профсоюзов неблагоприятной динамикой экономической ситуации в Италии. Согласно последнему докладу ОЭСР о состоянии и перспективах развития страны на ближайший период, ВВП в 2019 г. сократится на $0,2 \%$, бюджетный дефицит выйдет за согласованные с ЕС рамки, достигнув 2,5\%, государственный долг увеличится до $134 \%$ ВВП, безработица вырастет до $12 \%{ }^{2}$. Доклад рекомендует отказаться от изменения пенсионного законодательства и от введения плоской шкалы налогообложения.

Итальянское руководство отмахивается от этих рекомендаций. Его реакцию можно резюмировать как «не вмешивайтесь, мы знаем, что делаем». Деловой мир Италии, однако, обеспокоен тем, что пришедшие к власти популисты слишком упрощённо видят пути решения сложных проблем, стоящих перед страной в обостряющейся внешней обстановке. Италия безоружна перед лицом наступающего спада, считает бывший министр экономики П.-К. Падоан. Необходимо возобновить начавшиеся при правительстве ДП реформы, для чего нужен радикальный поворот в экономической политике и соглашение с ЕС. Самый плохой сценарий - игнорировать серьёзность момента, потому что ситуация может выйти из-под контроля и принести резкое ухудшение перспектив как в отношении роста экономики, так и в отношении государственного долга ${ }^{3}$.

Но если Италия, безусловно, должна возобновить структурные реформы (чего пока не видно), то и ЕС необходимо пересмотреть свою нынешнюю модель управления, считает С. Фаббрини, ведущий обозреватель газеты деловых кругов Италии Il Sole 24 Ore по европейским проблемам. Будущий Европарламент мог бы способствовать реализации европейских реформ, которые снизили бы градус противостояния. Италия заинтересована в завершении создания единого рынка в секторах энергетики и цифровой экономики, в образовании единого рынка капитала для расширения источников финансирования своей экономической и про-

ток (15), Центр (15), Юг (18) и острова Сицилия и Сардиния (8). Elezioni Europee, tutte le liste e I candidati all'Europarlamento. URL: http://www.today.it/politica/candidati-elezioni-europee-2019.html.

${ }_{1}^{1}$ Picchio N., Pogliotti G. Investimenti, appello alla UE da Confindustria e sindacati. Il Sole 24 Ore, 09.04.2019.

2 Trovati G. L'Ocse: l'Italia in stallo. Quota 100 va abrogate. Il flat tax non e' equa. Il Sole 24 Ore, 02.04.2019.

${ }^{3}$ Cellino M. La globalizzazione «corrosa» spaventa economist e imprese. Il Sole 24 Ore, 05.04.2019. 
мышленной деятельности. Европарламент должен также способствовать проведению новой промышленной политики в интересах повышения конкурентоспособности ЕС по отношению к США и Китаю. Но прежде всего необходимо инициировать реформу управления еврозоной (хотя последнее слово здесь принадлежит национальным правительствам); у неё должен быть собственный бюджет, опирающийся на прямое налогообложение, с помощью которого можно вести политику борьбы с безработицей и поддержания экономического роста (для Италии это два из трёх общепризнанных приоритетов, наряду с иммиграционной политикой). Нынешнее итальянское «диссидентство» имеет наряду с внутренними внешние причины, и для противостояния ему требуется коалиционная политика ЕС, совпадающая с национальными интересами Италии ${ }^{1}$.

Итальянскому проекту, как его называет Сальвини, не исполнилось и года, и хотя его контуры уже вполне определились, его еврокритический потенциал оценивать рано. Вероятно, на предстоящих выборах в Европарламент Италия внесёт заметный вклад в увеличение численности и веса евроскептиков и «суверенистов» в европейских структурах. В результате (но в ещё большей мере как следствие брекзита) прогнозируется утрата парламентского большинства двумя ведущими группами - Европейской народной партией и Европейской социалистической партией, однако это не помешает сохранению ими руководящей роли в Европарламенте $^{2}$. Большее значение имеет итальянский эксперимент противостояния ЕС в области бюджетной политики: опыт этой страны станет наглядной иллюстрацией того, какую реальную альтернативу нынешнему экономическому курсу ЕС может предложить фактический, на сегодняшний день, лидер еврокритического лагеря.

\section{Список литературы}

Cellino M. La globalizzazione «corrosa» spaventa economist e imprese. Il Sole 24 Ore, 05.04.2019.

Comprendre 1'Europe. URL: https://www.touteleurope.eu/actualite/a-quoi-ressemblera-le futurparlement-europeen.html.

D'Alimonte R. Prevale l'ala europeista. Il Sole 24 Ore, 19.02.2019.

Elezioni europee 2019. Servizio stampa, Direzione generale della Comunicazione. URL: www. europarl.europa.eu/pdfs/news/expert/2018/8/service/20180820SRV10205/elections-press-kit-it.pdf.

Elezioni europee 2019, I sondaggi di Sky TG 24: Lega al 32,1, Pd vicino al M5s. URL: https://tg24.sky.it/politica/photogallery/2019/04/01/sondaggi-elezioni-europee-2019.html\#0.

D'Alimonte R. Prevale l'ala europeista. Il Sole 24 Ore, 19.02.2019.

Elezioni Europee, tutte le liste e I candidati all'Europarlamento. URL: http://www.today.it/politica/candidati-elezioni-europee-2019.html.

Fabbrini S. Riforme in Europa, non soltanto in Italia. Il Sole 24 Ore, 31.03.2019.

Patta E. Pd: rischio Italexit, giu' il cuneo sul lavoro. Il Sole 24 Ore, 10.04.2019.

Picchio N., Pogliotti G. Investimenti, appello alla UE da Confindustria e sindacati. Il Sole 24 Ore, 09.04.2019.

Trovati G. L'Ocse: l'Italia in stallo. Quota 100 va abrogate. Il flat tax non e' equa. Il Sole 24 Ore, 02.04.2019.

\footnotetext{
${ }^{1}$ Fabbrini S. Riforme in Europa, non soltanto in Italia. Il Sole 24 Ore, 31.03.2019.

${ }^{2}$ D'Alimonte R. Prevale l'ala europeista. Il Sole 24 Ore, 19.02.2019.
} 


\section{References}

Cellino M. La globalizzazione «corrosa» spaventa economist e imprese. Il Sole 24 Ore, 05.04.2019.

Comprendre 1'Europe. URL: https://www.touteleurope.eu/actualite/a-quoi-ressemblera-le futurparlement-europeen.html.

D'Alimonte R. Prevale l'ala europeista. Il Sole 24 Ore, 19.02.2019.

Elezioni europee 2019. Servizio stampa, Direzione generale della Comunicazione. URL: www. europarl.europa.eu/pdfs/news/expert/2018/8/service/20180820SRV10205/elections-press-kit-it.pdf.

Elezioni europee 2019, I sondaggi di Sky TG 24: Lega al 32,1, Pd vicino al M5s. URL: https://tg24.sky.it/politica/photogallery/2019/04/01/sondaggi-elezioni-europee-2019.html\#0.

D'Alimonte R. Prevale l'ala europeista. Il Sole 24 Ore, 19.02.2019.

Elezioni Europee, tutte le liste e I candidati all'Europarlamento. URL: http://www.today.it/politica/candidati-elezioni-europee-2019.html.

Fabbrini S. Riforme in Europa, non soltanto in Italia. Il Sole 24 Ore, 31.03.2019.

Patta E. Pd: rischio Italexit, giu' il cuneo sul lavoro. Il Sole 24 Ore, 10.04.2019.

Picchio N., Pogliotti G. Investimenti, appello alla UE da Confindustria e sindacati. Il Sole 24 Ore, 09.04.2019.

Trovati G. L'Ocse: l'Italia in stallo. Quota 100 va abrogate. Il flat tax non e' equa. Il Sole 24 Ore, 02.04.2019.

\section{Italy at the Head of Eurocritics}

Author. Agnessa Avilova, Candidate of Sciences (Economics), Leading research fellow, Institute of World Economy and International Relations. Address: 23, Profsoyuznaya str., Moscow, Russia, 117997. E-mail: avi@imemo.ru.

Abstract. Italy is the only major EU country headed by an Eurocritic coalition government, which openly challenges the EU economic policy. Both of its leaders, competing with each other, develop ideas of «renewed Europe» and strive to create their own groups in the new European Parliament. Italian «Europeanists» cannot be a counterweight to Eurocritics in these elections. The business world of Italy is concerned about the simplistic approach of the political leadership to the problems of the country in a deteriorating economic situation. The near future will demonstrate the real significance of the alternative proposed by the Italian government.

Key words: Italy, Eurocritics, European Parliament, elections, Salvini, Di Maio.

DOI: http://dx.doi.org/10.15211/vestnikieran220193843 